\title{
WHAT REALLY DETERMINES POLISH EXPORTS? THE SEMI-MIXED EFFECTS GRAVITY MODEL FOR POLAND
}

The goal of this article is to investigate the determinants of the intensity of Polish exports with the use of the trade gravity approach in a panel data set covering the period 1999-2013. In an attempt to obtain unbiased results we utilize the semi-mixed effect method using PPML estimator as suggested by the recent empirical literature. In the basic version of the trade gravity model, we take into account the standard factors suggested by the literature of the subject. In its extended version, we control for additional factors including relative endowments of factors of production, a technological gap as measured by TFP and relative patenting performance, quality of institutions or impact of regional and bilateral trade agreements or exchange rate volatility. In most of the cases, the coefficients for the traditional gravity determinants are economically sensible and their impact on the dependent variable is statistically significant. The gravity approach proves to be a robust tool for identifying the determinants of trade intensity and thus for predicting future trade flows.

Keywords: trade gravity, Poland, panel data, semi-mixed effects, PPML

JEL Classifications: C23, F10, F14, F15

DOI: $10.15611 /$ aoe.2017.2.01

\section{INTRODUCTION}

Gravity has become the most important tool in international trade analysis over the years ${ }^{1}$. Other "flagship" trade theories are useful for determining the ground of exports/imports performances (specialization patterns and trade directions). However, it is gravity that enables to

* Faculty of Economics, Economics of European Integration Division; Institute for Development, University of Gdansk, Sopot.

${ }^{* *}$ Faculty of Management, Department of Econometrics, University of Gdansk.

${ }^{* * *}$ Faculty of Economic Sciences, University of Warsaw.

${ }^{1}$ The research was conducted and financed within the grant of the National Science Centre (NCN) entitled "An analysis of international trade of Poland in the light of new trade theories. Implications for economic policy in the crisis era" (2012/05/B/HS4/04209) chaired by Krystyna Gawlikowska-Hueckel. Furthermore, we would like to thank Jakub Kwiatkowski for his help with collecting the trade data. 
determine and predict actual trade flows or economic consequences of the establishments of preferential trade agreements. The gravity model is also used in interpretations of non-trade flows between countries, i.e. migration and FDI. The framework of the model is based on the analogy with the Newtonian theory of gravity reflecting the relationship between the intensity of trade between two partners, the size of their economies and the distance between them. The initial lack of clear theoretical underpinnings was solved in the 1980s (e.g. Bergstrand 1985). Recently the model went through a remarkable evolution in terms of empirical specification (for instance the heterogeneity theorem by Melitz (2003)).

After studying numbers of articles devoted to the issue of gravity, an important conclusion is that authors are rather flexible in their selection of variables (in particular independent variables) based on the context of their particular analyses. Apart from standard variables such as distance and economic potential, a set of specific variables is usually included. In international trade, these can be for instance: economic integration agreements, currency unions, access to the sea, historical circumstances as specific links between former metropolises and their colonies, the common language, common cultural heritage, etc. A very detailed description of the possible variables utilized in gravity equations was presented by Kepaptsoglou, Karlaftis and Tsamboulas (2010). A thorough examination of the gravity theory, as well as empirical tools and methods, was given by Head and Mayer (2014).

Gravity models are characterised by the possibility to interpret coefficients as elasticities, which is a positive aspect - however, it may somehow create interpretational problems of the models' parameters. The issue of the proper specification of the empirical model has been one of the most important issues for the last twenty years (e.g. Matyas 1997; Egger and Pfaffermayr 2003). Silva and Tenreyro (2006) in their seminal article raised a problem that had been ignored by both the theoretical and applied studies. In particular, they argued, that the logarithmic transformation of the original model is not a relevant approach to estimate elasticities. The multiplicative trade models with multiplicative error do not satisfy the assumption of the homoscedasticity of the error term since there is a dependency between the error term of the transformed log-linear model and the regressors, which finally causes inconsistency of the ordinary least squares estimator or the random and fixed effects estimator. As an alternative, the authors propose the estimation of the gravity model in levels using the Poisson pseudomaximum likelihood estimator. Moreover, more recently Proença et al. 
(2015) suggested a semi-mixed effects method which relaxes the very strict assumptions of the random effects model but keeps more restrictions than the standard fixed effect model. Therefore we select the latter as the most relevant approach to study the determinants of the intensity of bilateral trade flows of Poland with its trade partners all over the world in in the period 1999-2013.

The rest of the paper is organised as follows. Section 2 reviews the issue of the proper estimation procedure. Section 3 presents a model for empirical analyses and describes the data sources utilized. Section 4 discusses the estimation results. The last section concludes.

\section{THE ISSUE OF THE PROPER ESTIMATION PROCEDURE}

There has been plenty of theoretical and empirical studies focusing on estimation procedures that fit the gravity models for bilateral trade using cross-sections of panel data ${ }^{2}$. The discussion refers especially to the correct econometric specification of the model as well as the appropriate estimation method. The simplest form of the gravity equation for trade, relevant to Tinbergen's (1962) approach, states that the trade flows from country $i$ to country $j$, denoted by $T_{i j}$, is proportional to the GDPs of the two countries' $\left(Y_{i}, Y_{j}\right)$ and inversely proportional to the distance between the countries, $D_{i j}$. However, it should be taken into account that the trade is not the same as the physical force of gravity, at least because it depends on many uncertainties connected with economic and social activities, therefore it should be treated as a stochastic process.

Furthermore, Anderson and van Wincoop (2003) argued that the traditional gravity equation is not correctly specified as it does not take into account additional variables representing the specific effects of the exporter and importer. That is why in most of the empirical studies the gravity model is extended in order to include many other variables (economic, socioeconomic, geographical) that could potentially impact trade flows. As explained above, the set of variables consists of the binary time-invariant $D_{i j}$ (similar to the distance), nonbinary time-invariant information $Z_{i j}$, and other time-varying variables which may vary also over $i, j$ or both $(i, j)$, denoted as $X_{i j t}$. Additionally, within the panel data framework, it is possible to include unobserved individual $(i)$ and time $(t)$ effects as well as effects for pairs of

\footnotetext{
${ }^{2}$ A review of such analyses was presented for example by Proenca, Sperlich and Savasci (2015).
} 
countries $(i, j)$. At the same time, all of them may be treated as fixed or random. Such models are defined as three-way effect panel data models.

The stochastic version of the panel data gravity equation has the following form:

$$
T_{i j t}=\alpha_{0} Y_{i t}^{\beta_{1}} Y_{j t}^{\beta_{2}} Z_{i j}^{\gamma} X_{i j t}^{\alpha} e^{\delta D_{i j}+v_{t}+\eta_{i j}} \varepsilon_{i j t},
$$

where $v_{t}$ are time effects which could account for business cycles, $\eta_{i j}$ are unobserved heterogeneity effects, and $\varepsilon_{i t}$ is the stochastic effort term. Further, $\alpha_{0}, \beta_{1}, \beta_{2}, \gamma, \alpha, \delta$ are unknown coefficients.

There has been a long tradition in the trade literature of log-linearizing equation (1) and estimating the parameters of interest by OLS, using the equation:

$$
\begin{gathered}
\ln T_{i j t}=\ln \alpha_{0}+\beta_{1} \ln Y_{i t}+\beta_{2} \ln Y_{j t}+\gamma \ln Z_{i j} \\
+\alpha \ln X_{i j t}+\delta D_{i j}+v_{t}+\eta_{i j}+\ln \varepsilon_{i j t}
\end{gathered}
$$

But, as Santos Silva and Tenreyro (2006) argue, the validity of the procedure depends critically on the assumption that $\ln \varepsilon_{i j t}$ are statistically independent on the repressors. When the assumption is not valid, the OLS estimation is inconsistent and biased. The problem has been ignored so far both in the theoretical and in applied analyses. In reality, the issue of heteroscedasticity is quantitatively and qualitatively important in most gravity models even if fixed effects are controlled for. Hence the variance in the error term $\varepsilon_{i j t}$ in equation (2) depends on $Y_{i}, Y_{j}, D_{i j}$ and other variables, this means that the expected value of $\ln \varepsilon_{i j t}$ will also depend on the repressors, violating the condition for consistency of OLS. This suggests that this estimation method leads to inconsistent estimates of the elasticities of interest.

Another problem connected with the estimation of the log-linearizing gravity equation are zero trade flows - observed trade between some pairs of countries is equal to zero because the countries did not trade in a given period or the value of trade was very low. The existence of observations for which the dependent variable is zero creates a problem for the use of the loglinear form of the gravity equation. Several methods have been developed to deal with this problem. The first simple approach is to drop the pairs with zero trade from the data set, but then the results of the estimation are not reliable as some information is omitted. The second method is to use $T_{i j t}+1$ 
as the dependent variable in the regression, however, rescaling of the data leads to an inaccurate estimation of the results. The next solution, used for instance by Frankel and Wei (1993), is to estimate the multiplicative equation using nonlinear least squares (NLS), which is an asymptotically valid estimator for equation (1). However, the NSL can be very inefficient in this context as it ignores the heteroscedasticity in the data (see Santos Silva and Tenreyro 2006).

As a solution to both of the estimation problems described above (inconsistency of the OLS and zero flows), Santos Silva and Tenreyro (2006) proposed the Poisson pseudo-maximum-likelihood (PPML) estimator, which is often used for counting data. They notice that if economic theory suggests that $y$ and $x$ are linked by a constant-elasticity model of the form $y_{i}=\exp \left(x_{i} \beta\right)$, the function $\exp \left(x_{i} \beta\right)$ can be interpreted as the conditional expectation of yi given $\mathrm{x}$, denoted $\mathrm{E}\left[y_{i} \mid x\right]$. A possible way of obtaining an efficient estimate of the parameters of interest is the use of the pseudo-maximum-likelihood (PML) estimator based on some assumption on the functional form of $\mathrm{V}\left[y_{i} \mid x\right]$. Under the assumption that the conditional variance is proportional to the conditional mean, $\beta$ can be estimated by solving the following set of first-order conditions:

$$
\sum_{i=1}^{n}\left[y_{i}-\exp \left(x_{i} \tilde{\beta}\right)\right] x_{i}=0 .
$$

The authors claim that for this estimator the data do not have to be Poisson and $y_{i}$ does not have to be an integer for the estimator based on the Poisson likelihood function to be consistent. Additionally, the use of the estimator eliminates the problem of zero flows ${ }^{3}$ Westerlund and Wilhelmsson (2009) also emphasized that the PPML estimator is a solution to overcome the problem of zero trade flow observations.

The estimating regression of gravity model using PPML method has the following form:

$$
\begin{gathered}
T_{i j t}=\exp \left[\ln \alpha_{0}+\beta_{1} \ln Y_{i t}+\beta_{2} \ln Y_{j t}+\gamma \ln Z_{i j}+\alpha \ln X_{i j t}\right. \\
\left.+\delta D_{i j}+v_{t}+\eta_{i j}\right] \varepsilon_{i j t}
\end{gathered}
$$

\footnotetext{
${ }^{3}$ It should be noted that there are some studies raising some doubt on the generality of the estimator for empirical trade models. For example, Martinez-Zarzoso (2013) shows that in several situations feasible GLS combined with the log-transformation can have a better performance than PPML.
} 
It should be noted that in regression (4) the time effects, $v_{t}$, and countrypair specific effects $\eta_{i j}$ are estimated as fixed effects which cause that some of the time-invariant effects cannot be estimated.

Another extension of the gravity model estimation is proposed by Savasci (2011) who suggests estimating equation (4) with the aid of a mixed effect PPML, where the pair effects $\eta_{i j}$ are random effects to control for unobserved cross-section heterogeneity. The obvious problem that occurs in such a model is to prevent misspecification due to the independence assumption for the random effects. But in the context of small area statistics, Lombardia and Sperlich (2011) introduced a new class of semi-mixed effects models. In terms of panel econometrics, one could say that they extended the Mundlak device for random effects models.

In accordance with the results of the above discussion, the estimation of all gravity models presented in the present article has been performed using the PPML procedure with robust standard errors in Stata (StataCorp. 2011).

\section{THE EMPIRICAL MODEL AND DATA SOURCES}

In their classic article, Anderson and Wincoop (2004) used export shares of trade partners in order to estimate the strength of gravity. The use of the county-pair effect allowed to eliminate the potential bias of mutual resistance described in the literature of the subject. An alternative approach, however, can be utilized (e.g. Helpman, Melitz and Rubinstein 2008), in which the values of total trade flows are utilized. In our study, the value of exports from Poland to a given trade partner in million EUR is the explained variable $\left(\right.$ Export $\left._{i j t}\right)$.

The estimated empirical panel model with country-pair effects for total export takes the following general form:

$$
\begin{aligned}
& \text { Export }_{i j t}= \\
& \exp \left[\ln \alpha_{0}+\beta_{1} \ln Y_{j t}+\beta_{2} \ln D_{i j}+\gamma \ln X_{i j t}+\rho \ln Z_{i j}+v_{t}+\eta_{i j}\right] \varepsilon_{i j t}
\end{aligned}
$$

where $Y_{j}$ is the size of the partner, $D_{i j}$ is the distance to partner, and $X_{i j t}$ is the conditioning set of variables describing bilateral trade relations.

The basic explanatory variables include the size of partner as measured by the log of real GDP (real GDP) or log of the population (population) and the log of the distance between trade partners (distance). The distance is 
proxied by geographical "as the crow flies" distance from Warsaw to trading partner's capital (in kilometres).

Two countries of similar size (as measured by real GDP) should trade more than two countries of dissimilar sizes. Helpman and Krugman (1985) have shown that the smaller the difference in the relative size of economies, the larger the volume of mutual trade, and the greater intensity of intraindustry trade. This is due to the fact that, as economies become more similar in terms of their market size, the potential for overlapping demand for differentiated products is enhanced.

In the present study, we adopt two different measures of similarity and expect the obtained coefficients to be statistically significant and positive. The first one, sim, is calculated using the following formula utilizing data on GDP of Poland $Y_{i}$ and the trade partner $Y_{j}$ :

$$
\operatorname{sim}_{i j}=\ln \left|1-\left(\frac{Y_{i}}{Y_{i}+Y_{j}}\right)^{2}-\left(\frac{Y_{j}}{Y_{i}+Y_{j}}\right)^{2}\right|
$$

Secondly, following Balassa and Bauwens (1988), we calculate the difference in GDP of Poland $Y_{i}$ and its trading partner $Y_{j}, D I F E_{i j}$, as follows:

$$
D I F E_{i j}=1+\frac{w_{i j} \ln \left(w_{i j}\right)+\left(1-w_{i j}\right) \ln \left(1-w_{i j}\right)}{\ln 2}
$$

where $w_{i j}=\frac{Y_{i}}{Y_{i}+Y_{j}}$.

At the same time, two countries at a similar level of development should trade more intensely that countries characterized by a significant gap in the level of development. In accordance with the tradition in the empirical literature of the subject, real GDP per capita can be treated as a rough measure of the level of development. We adopt the following measure of the gap in the level of development ( $r l f)$ and expect its coefficient to be statistically significant and negative. An increase in the gap should decrease the intensity of bilateral trade and thus negatively influence Polish exports.

$$
r l f=\ln \left|y p c_{j}-y p c_{i}\right|
$$

We furthermore utilize a number of dummy variables for adjacency, border or preferential trade agreements. Utilizing data from PWT 8.0 we further control for differences in factor endowments or differences in productivity. 


\section{Data sources}

We utilize Comext data set as a principal source of trade data. Comext is a statistical database on intra-EU and extra-EU trade of goods managed by Eurostat, the Statistical Office of the European Commission.

For the set of explanatory variables, we utilize a number of data sources, the most important being the Penn World Tables 8.0 by Feenstra et al. (2013). We also utilize data sets of World Development Indicators (WDI) and Worldwide Governance Indicators dataset (WGI) compiled by Kaufmann et al. (2010), both provided by the World Bank. The data for patent applications come from the United States Patent and Trademark Office (USPTO). The OECD migration database has been utilized in order to account for the size of the Polish diaspora.

\section{ECONOMETRIC RESULTS AND DISCUSSION}

The estimation of the basic and extended specifications of the empirical model has been performed using a semi-mixed effects method suggested in a recent article by Proença et al. (2015) with a dummy variable for membership in the EU (EU) serving as a clustering variable. The estimation was carried out in STATA 12. The results are provided in Tables 1 and 2.

The analysis is carried out for 234 trade partners of Poland in the period 1999-2013. The explained variable is the value of exports from Poland in EUR million. The usual zero adjustment is not necessary as we take into account the level of exports and not the standard log of exports.

Various specifications of the model were tested. The number of specifications shown in the article has been restricted for obvious reasons. The results are not sensitive to the inclusion of time effects. As they do not significantly increase the fit of the model we have decided not to present them. The general fit of the model is high - explaining from 76 to 93 percent of the variation in exports depending on the specification. The results are robust to potential modifications.

In most of the analysed specifications the coefficients of traditional variables such as real GDP of a trade partner, and the distance between Poland and the partner are economically sensible and their impact on the dependent variable is statistically significant. The intensity of Polish exports decreases with distance to the trade partner, and increases with the partner's size - larger countries tend to import more from Poland. As expected, geographical proximity has been shown to be an important determinant of 
bilateral trade flows as it can be associated with lower transportation and information costs.

The impact of membership in the European Union $(E U)$ is clearly positive and statistically significant. Poland exports more, ceteris paribus, to partners from within the internal market of the European Union (free flow of goods and services within the free trade area and common market rules). We would like to stress here once again that $\mathrm{EU}$ is our clustering variable in the semi-mixed effects setting.

The impact of the gap in the level of development as shown by $r f l$ is negative, as expected in most of the specifications. This is statistically significant, however only in a few of the specifications of the empirical model. All in all, Poland tends to export more to countries at a similar level of development.

As the index of similarity ( $\mathrm{sim}$ ) is correlated with a log of real GDP, in order to test the Helpman and Krugman hypothesis we include in model M2 a logarithm of the population (population) as a measure of partners size. The coefficient of sim, however, is not statistically significant which is to some extent surprising. The result, as was checked, to a large extent depends on the utilized estimation method. This is also the case with DIME (M3).

Adjacency plays a significant role as expected. Poland exports more to neighbouring countries - the impact of both border and border length is positive and statistically significant at 1 percent level (M4 and M5). The border effect has been thus positively verified.

The coefficient of the Eurozone dummy (euro) is positive but statistically insignificant (M6). This could be due to the inclusion of a dummy for EU partner countries. If we drop it, the coefficient of euro becomes positive and statistically significant. The result yields support for the existence of the socalled Rose effect (Frankel and Rose 2002). Taking into account that already most of the Polish exports go to the Eurozone, as well as the gradual expansion of the Eurozone, the costs of staying outside of the single currency area in terms of the unutilized export potential could be judged as rather high. We thus expect a significant increase in Polish exports to the Eurozone after the adoption of the common currency.

Furthermore, Poland exports more (M7), ceteris paribus, to countries with better quality of institutions as proxied by rule of law. We have selected this proxy for the quality of institutions from the set of alternatives provided by the Governance Indicators database of the World Bank as it was most frequently utilized in the empirical analysis of development. 
The impact of exchange rate volatility on Polish exports as measured by the log of the standard deviation of daily exchange rates of PLN observed over a period of a year (S volatility) is negative but not statistically significant (M8). The impact of volatility to USD ( $x r)$, available from PWT 8.0 is however significant and has the presumed direction (M9). Less volatility in the forex market clearly stimulates bilateral trade.

The size of the Polish migrant community as proxied by the log of Polish migrants in a given partner country (diaspora) has a surprisingly negative and significant impact on Polish exports (M10). The data is available only for a limited number of partner economies from the OECD which can clearly bias the results.

The next three specifications (M11-M13, please refer to Table 2) analyse the impact on the intensity of Polish exports of the difference or the gap between Poland and its trade partners in factor endowments, productivity and technological sophistication.

First of all, the greater difference in the capital-labour ratio (dif $\mathrm{K} / \mathrm{L}$ ratio) has a robust and positive impact on the intensity of Polish exports. This could point to the still important significance of traditional factor endowments differences as postulated by the HO theory and its modern extensions (Heckscher and Ohlin 1991) in explaining a significant fraction of Polish trade relations.

Secondly, the greater difference in productivity levels as measured by total factor productivity ratios (dif TFPratio) decreases Polish export intensity. We could thus infer that Poland seems to export more to countries at a similar level of productivity and thus technological sophistication.

Thirdly, the impact of the technological gap as measured by the log of absolute difference in relative patent applications (patent applications per 1 million population) in the United States Patent and Trademark Office (dif abs $C U M P)$ is statistically insignificant. We treat the ability to the patent in the USPTO as a rough proxy for technological sophistication and the proximity to the world technology frontiers. We would like to stress that the results are sensitive to the method of accounting for the gap and the method of estimation.

Last but not least, the results concerning the impact of regional or bilateral trade agreements need a longer comment (please refer to models M14-M15). First of all, we have to take into account that most of the Polish exports have an intra-EU nature with Eurozone's member states (and in particular Germany) playing the most important role. The trade flows within the EU are regulated by common market rules. If we account for free trade 
areas (FTA), customs unions $(C U)$ as well as economic integration agreements $(E I A)$ with extra-EU states, the impact of all is positive but statistically significant only for FTAs. In interpreting the results we have to remember that in our panel the first four years (1999-2003) is the period directly preceding Poland's entry into the EU and thus preceding the adoption of common trade policy rules. At the same time, we have to bear in mind that the FTA in manufacturing goods with the EU, the most important trade partner, entered fully into force in January 2002.

If we extend the analysis to all Regional Trade Agreements (RTA) and control for specific relations with Post-Soviet countries (post-Soviet), the impact of RTA on the dependent variable is positive and significant at 5 percent level (model M15). The establishment of RTA has a robust and positive impact on Polish exports.

In the last specification, M16, we account for the overall level of competitiveness as indicated by the value of Global Competitiveness Index calculated by WEF ( $G W C I$ ) - the weighted index of twelve basic pillars of competitiveness (Schwab 2014). The impact on the dependent variable of interest to us is statistically significant and positive in accordance with our expectations.

\section{CONCLUSIONS}

The goal of this article was to investigate the determinants of the intensity of Polish exports to its trade partners (country level). The analysis was carried out for 234 trade partners of Poland in the period 1999-2013 with the use of panel gravity modelling. We utilized a newly suggested (Proença et al. 2015) and superior semi-mixed effects panel approach with the Poisson pseudo-maximum-likelihood estimator. EU membership (EU) played the role of the clustering variable.

The gravity framework proved to be robust. The fit of the empirical model was high. The impact of standard determinants of gravity was highly statistically significant and in accordance with general expectations. The hypothesis on the positive impact of size similarity was not supported. Adjacency had a robust and positive impact on Polish exports thus supporting the notion of the border effect. This applied as well to EU membership and membership in the eurozone (responsible presently for most of the Polish exports with the dominant role of Germany - Poland's main trade partner). The results gave support to the Rose effect. 
In the extended version of the model, we controlled for additional factors including relative endowments of factors of production, a technological gap as measured by TFP and relative patenting performance in the USPTO (at the global technology frontier), quality of institutions, exchange rate volatility and the impact of regional and bilateral trade agreements. Exchange rate volatility had, as had been expected, a negative impact on exports. The greater difference in capital to labour $(\mathrm{K} / \mathrm{L})$ ratio had a robust and positive impact on the intensity of Polish exports, which could point to the significance of traditional factor endowments differences as postulated by the $\mathrm{HO}$ theory. At the same time, Poland seemed to export more to countries at a similar level of productivity and thus technological sophistication.

Some of the obtained results were surprising, such as the negative impact of Polish diaspora, and thus require further investigation. The present study will be deepened and extended along several dimensions in order to account better for the technological gap and sectoral heterogeneity.

\section{REFERENCES}

Anderson, J., Van Wincoop, E., Gravity with Gravitas: A Solution to the Border Puzzle, “American Economic Review”, Vol. 93(1), pp. 170-192, 2003.

Anderson, J., The Gravity Model, “Annual Review of Economics”, Vol. 3(1), pp. 133-160, 2011.

Balassa, B., Bauwens, L., Changing Trade Patterns in Manufactured Goods: An Econometric Investigation. North Holland, Amsterdam, 1988.

Bergstrand, J. H., The Gravity Equation in International Trade: Some Microeconomic Foundations and Empirical Evidence, "The Review of Economics and Statistics", pp. Vol. 67 (3), pp. 474-481, 1985.

Egger, P., Pfaffermayr, M., The Proper Panel Econometric Specification of the Gravity Equation: A Three-way Model with Bilateral Interaction Effects, "Empirical Economics", Vol. 28(3), pp. 571-580, 2003.

Feenstra, R. et al., The Next Generation of the Penn World Table, NBER Working Paper no. 19255, 2013.

Frankel, J., Wei, S., Trade Blocs and Currency Blocs, NBER Working Paper no. 4335, 1993.

Frankel, J., Rose, A., An Estimate of the Effect of Common Currencies on Trade and Income, "Quarterly Journal of Economics", pp. 437-466, 2002.

Gopinath, G., Helpman, E., Rogoff, K., The Handbook of International Economics, Vol. 4, Elsevier, North-Holland, 2004.

Head, K., Mayer, T., Gravity Equations: Workhorse, Toolkit, and Cookbook [in:] Gopinath, G., Helpman, E., Rogoff, K., The Handbook of International Economics, Vol. 4. Elsevier, North-Holland, 2014. 
Heckscher, E. F., Ohlin, B. G., Heckscher-Ohlin Trade Theory, MIT Press, Cambridge, 1991. Helpman E., Krugman, P., Market Structure and Foreign Trade, MIT Press, Cambridge, 1985.

Helpman, E., Melitz, M. J., Rubinstein, Y., Estimating Trade Flows: Trading Partners and Trading Volumes, "Quarterly Journal of Economics", Vol. 73, pp. 441-486, 2008.

Helpman, H., Imperfect Competition and International Trade. Evidence from Fourteen Industrial Countries, "Journal of the Japanese and International Economies", Vo1. 1, pp. 62-81, 1987.

Kaufmann, D. et al., The Worldwide Governance Indicators: Methodology and Analytical Issues, World Bank Policy Research Working Paper No. 5430, 2010.

Kepaptsoglou, K., Karlaftis, M. G., Tsamboulas, D., The Gravity Model Specification for Modeling International Trade Flows and Free Trade Agreement Effects: A 10-Year Review of Empirical Studies, "The Open Economics Journal”, Vol. 3, pp. 1-13, 2010.

Lombardía, M. J., Sperlich, S., A New Class of Semi-mixed Models and Its Application in Small Area Estimation, “Computable Statistical Data Analysis”, Vol. 56, pp. 2903-2917, 2012.

Martinez-Zarzoso, I., The Log of Gravity Revisited, “Applied Economics”, Vol. 45, pp. 311$-327,2013$.

Matyas, L., Proper Econometric Specification of the Gravity Model, "The World Economy", Vol. 20(3), pp. 363-368, 1997.

Melitz, M. J., The Impact of Trade on Intra-industry Reallocations and Aggregate Industry Productivity, "Econometrica", Vol. 71(6), pp. 1695-1725, 2003.

Proença, I. et al., Semi-mixed Effects Gravity Models for Bilateral Trade, "Empirical Economics", Vol. 48(1), pp. 361-387, 2015.

Santos Silva, J., Tenreyro, S., The Log of Gravity, "The Review of Economics and Statistics", Vol. 88 (4), pp. 641-658, 2006.

Savaşc1, D., Three Studies on Semi-mixed Effects Models, Dissertation presented for the degree of Doctor of Philosophy at the Faculty of Economic Sciences of the GeorgAugust-Universität Göttingen, 2011.

Schwab, K., The Global Competitiveness Report 2014-2015: Full Data Edition. World Economic Forum, Davos, 2014.

Tinbergen, J., The World Economy. Suggestions for an International Economic Policy. Twentieth Century Fund, New York, 1962.

Westerlund, J., Wilhelmsson, F. (2009), Estimating the Gravity Model without Gravity Using Panel Data, “Applied Economics”, Vol. 43, pp. 641-649, 2009.

Received: December 2015 
APPENDIX

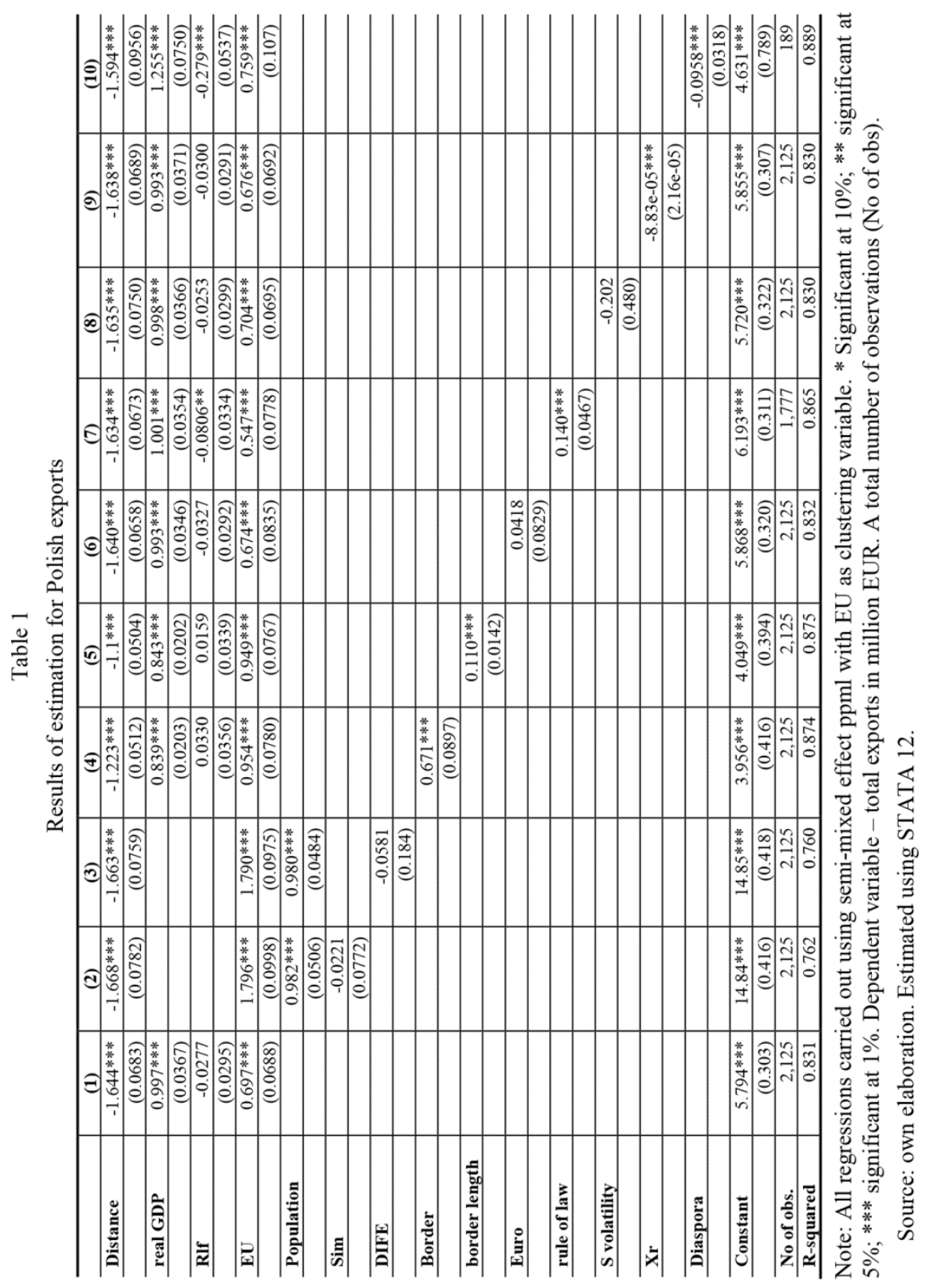


Table 2

Results of estimation for Polish exports

\begin{tabular}{|c|c|c|c|c|c|c|}
\hline & (11) & (12) & (13) & (14) & (15) & (16) \\
\hline \multirow[t]{2}{*}{ distance } & $-1.655 * * *$ & $-1.641^{* * *}$ & $-1.642 * * *$ & $-1.594 * * *$ & $-1.619 * * *$ & $-1.663 * * *$ \\
\hline & $(0.0594)$ & $(0.0659)$ & $(0.0688)$ & $(0.0717)$ & $(0.0748)$ & $(0.0729)$ \\
\hline \multirow[t]{2}{*}{ real GDP } & $1.009 * * *$ & $1.016^{* * *}$ & $0.992 * * *$ & $1.020^{* * *}$ & $0.992 * * *$ & $0.991 * * *$ \\
\hline & $(0.0301)$ & $(0.0387)$ & $(0.0360)$ & $(0.0378)$ & $(0.0375)$ & $(0.0301)$ \\
\hline \multirow[t]{2}{*}{ rlf } & 0.0443 & -0.0358 & $-0.0651^{* *}$ & -0.0231 & -0.00935 & -0.0147 \\
\hline & $(0.0287)$ & $(0.0305)$ & $(0.0318)$ & $(0.0267)$ & $(0.0313)$ & $(0.0392)$ \\
\hline \multirow[t]{2}{*}{$\mathbf{E U}$} & $0.543 * * *$ & $0.756 * * *$ & $0.658 * * *$ & $0.797 * * *$ & $0.764 * * *$ & $0.604 * * *$ \\
\hline & $(0.0637)$ & $(0.0770)$ & $(0.0727)$ & $(0.0830)$ & $(0.0726)$ & $(0.0780)$ \\
\hline \multirow[t]{2}{*}{ dif K/Lratio } & $1.682 * * *$ & & & & & \\
\hline & $(0.147)$ & & & & & \\
\hline \multirow[t]{2}{*}{ dif TFP ratio } & & $-0.663 * * *$ & & & & \\
\hline & & $(0.215)$ & & & & \\
\hline \multirow[t]{2}{*}{ dif abs CUMP } & & & 0.0274 & & & \\
\hline & & & $(0.0168)$ & & & \\
\hline \multirow[t]{2}{*}{ FTA } & & & & $0.272 * * *$ & & \\
\hline & & & & $(0.0767)$ & & \\
\hline \multirow[t]{2}{*}{$\mathbf{C U}$} & & & & 0.0628 & & \\
\hline & & & & $(0.121)$ & & \\
\hline \multirow[t]{2}{*}{ EIA } & & & & 0.187 & & \\
\hline & & & & $(0.114)$ & & \\
\hline \multirow[t]{2}{*}{ RTA } & & & & & $0.00912 * *$ & \\
\hline & & & & & $(0.00458)$ & \\
\hline \multirow[t]{2}{*}{ Post Soviet } & & & & & 0.137 & \\
\hline & & & & & $(0.0944)$ & \\
\hline \multirow[t]{2}{*}{ GWCI } & & & & & & $0.120 * *$ \\
\hline & & & & & & $(0.0554)$ \\
\hline \multirow[t]{2}{*}{ Constant } & $-2.806 * * *$ & $6.006 * * *$ & $6.051^{* * *}$ & $4.978 * * *$ & $5.447 * * *$ & $5.641 * * *$ \\
\hline & $(0.792)$ & $(0.298)$ & $(0.287)$ & $(0.393)$ & $(0.382)$ & $(0.400)$ \\
\hline No of obs. & 2,125 & 2,125 & 2,125 & 2,125 & 2,125 & 736 \\
\hline R-squared & 0.906 & 0.845 & 0.834 & 0.836 & 0.829 & 0.931 \\
\hline
\end{tabular}

Note: All regressions carried out using semi-mixed effect ppml with EU as clustering variable. * Significant at $10 \%$; ** significant at $5 \%$; *** significant at $1 \%$. Dependent variable - total exports in EUR million. A total number of observations (No of obs).

Source: own elaboration. Estimated using STATA 12. 